\title{
Preference between fixed-interval and variable-interval schedules of reinforcement: Separate roles of temporal scaling and predictability
}

\author{
PAUL W. FRANKEL and WALTER VOM SAAL \\ Princeton University, Princeton, New Jersey 08540
}

\begin{abstract}
Pigeons' preference between fixed-interval and variable-interval schedules was examined using a concurrent-chains procedure. Responses to two concurrently available keys in the initial links of the concurrent chains occasionally produced terminal links where further responses were reinforced under either a fixed- or variable-interval schedule. In previous studies, preferences for the variable schedule with such a procedure have been interpreted as reflecting a temporal scaling process that heavily weights the shorter intervals in the variable schedule. The present experiment examined whether predictability, i.e., the presence of external stimuli correlated with the reinforcement interval, might also influence preference in such situations. When the two intervals in a variable schedule were made predictable by being associated with different key colors, preference for that schedule increased. This increase was reliable but small in magnitude and transient when initial-link responses only occasionally produced terminal links; it was large in magnitude when only one response in the initial link was required to produce the appropriate terminal-link schedule. The results suggest that preference between fixed and variable schedules may be influenced both by temporal scaling and to a lesser extent by predictability of the reinforcement intervals.
\end{abstract}

A method widely used for the study of preference is the concurrent-chains procedure (Herrnstein, 1964a). In this procedure, responses to two concurrently available keys in an initial link occasionally produce terminal links in which only one key is lit and further responding produces primary reinforcement according to some schedule. Two different schedules of primary reinforcement are normally available, one for responses to the left key in the initial link and one for responses to the right key in the initial link. The distribution of responses to the two keys in the initial link may therefore be taken as a measure of preference for the two schedules of primary reinforcement available in the terminal links.

An early finding with this procedure was that variableinterval (VI) schedules were preferred over fixed-interval (FI) schedules, even when the average interreinforcement interval was the same in both schedules (Herrnstein, 1964b). This showed that subjects' preference is not accurately described in terms of the arithmetic average of the intervals comprising the VI schedule, but rather in terms of some scaling or transformation that weights the shorter intervals more heavily. A large number of subsequent experiments examining preference for different schedules of reinforcement have sought to determine the appropriate transformation that would describe the observed preferences. Herrnstein (1964b) found that a logarithmic transformation was not entirely satisfactory. Subsequently, Killeen (1968) found that a harmonic mean accounted for his data,

This research and preparation of this article were supported by NIMH Grant MH 22161 and NSF Grant GB 36975 to Walter vom Saal. Paul W. Frankel is now at Peter Bent Brigham Hospital, Boston, Massachusetts. Reprints may be obtained from Walter vom Saal, Department of Psychology. Millersville State College, Millersville, Pennsylvania 17551. while Davison (1969), using a special case of the VI schedule with only two values, found that preferences in his experiment were best described by a transformation based on the cube of the reciprocals of the intervals. Several other studies have examined choice between different combinations of both fixed and variableinterval and ratio schedules (Davison, 1972; Duncan \& Fantino, 1970; Fantino, 1967, 1969; see also Navarick \& Fantino, 1972). However, no consistent transformation has yet been found that is adequate to account for more that a limited set of data, and we can agree with Davison that "the problem of specifying an appropriate measure of reinforcement rate in the terminal links of concurrent-chain schedules has not yet been solved" (Davison, 1969 , p. 252).

The above studies have all assumed that choice between FI and VI schedules is influenced by the sub. ject's temporal scaling of the intervals comprising the schedules and have been aimed at finding a mathematical expression that adequately describes this scaling. Another difference between fixed and variable schedules that may influence preference is one of predictability: external stimuli are correlated with the reinforcement interval in FI schedules but not in VI schedules. A study by Bower, McLean, and Meacham (1966) suggests that differences in predictability may significantly affect preference. Using a modified concurrent-chains procedure, these authors found that subjects preferred an alternative followed by either an FI 10-sec schedule on a green key or an FI 40-sec schedule on a red key over an alternative followed by either FI 10-sec or FI 40-sec both on a yellow key. In other words, they preferred predictable to unpredictable reinforcement, even though in either case they had to wait the same amount of time 
Table 1

Sequence of Experimental Procedures

\begin{tabular}{|c|c|c|c|c|c|}
\hline Condition & $\begin{array}{c}\text { Number } \\
\text { of Sessions }\end{array}$ & $\begin{array}{c}\text { Initial-Link } \\
\text { Schedule } \\
\text { (in sec) }\end{array}$ & $\begin{array}{c}\text { Terminal-Link Sch } \\
\text { Left Key }\end{array}$ & $\begin{array}{l}\text { e (in sec) } \\
\text { Right Key }\end{array}$ & Description \\
\hline A & 18 & VI 60 & $\mathrm{Y}(15,45)$ & $Y(18.7)$ & Baseline: variable vs. fixed \\
\hline B & 18 & VI 60 & $R(15,45) ; G(15,45)$ & $Y(18.7)$ & Color irrelevant: Test for color preference \\
\hline $\mathrm{C}$ & 18 & VI 60 & $\mathrm{R}(15) ; \mathrm{G}(45)$ & $Y(18.7)$ & Color relevant: Test predictability \\
\hline D & 18 & VI 60 & $R(15) ; G(45)$ & $Y(15,45)$ & Test predictability \\
\hline $\mathrm{E}$ & 12 & FR 1 & $\mathrm{Y}(15,45)$ & $Y(15,45)$ & Baseline with FR 1 initial links \\
\hline $\bar{F}$ & 9 & FR 1 & $R(15) ; G(45)$ & $Y(15,45)$ & Test predictability \\
\hline
\end{tabular}

Note. Initial-link responses produced terminal links either under independent VI 60-sec schedules or under FR 1 schedules. Response keys in initial links were white. Response keys in terminal links could be either yellow $(Y)$, red $(R)$, or green $(G)$, and reinforcement intervals in the presence of those colors were either fixed at one value or were one of two values presented at random. For example, $Y(18.7)$ indicates yellow key with reinforcement interval fixed at $18.7 \mathrm{sec} ; Y(15.45)$ indicates yellow key with reinforcement interval alternating randomly between 15 and $45 \mathrm{sec}$. When two colors are indicated, the key was each color half the time, in a random order.

\section{to reinforcement.}

It is possible that previous experiments examining choice between FI and VI schedules were also influenced by preference for predictability. Choice in these studies may have been a result of two factors: temporal scaling, which strongly favors the variable schedule, and predictability, which favors the fixed schedule. If this were so, previous studies would have underestimated the preference for the variable schedule attributable to temporal scaling factors, since this preference was diminished by the factor of predictability which favored the fixed schedule. The present experiment examined whether preference for predictability in fact plays a role when preference for FI vs. VI schedules is examined in a concurrent-chains procedure.

\section{METHOD}

\section{Design}

The sequence of experimental conditions is shown in Table 1. Condition $\mathrm{A}$ was analogous to the procedure used by Davison (1969), with an FI schedule on the left key and a VI schedule consisting of two intervals (sometimes called a "mixed-interval" schedule) on the right key. The interval used here on the right key was chosen to yield approximately equal preference in the initial links according to Davison's (1969) formula. In Condition $B$ the colors to be used subsequently were made irrelevant simply as a control that color preferences would not influence subsequent results. The first critical condition is Condition $\mathrm{C}$, in which reinforcement intervals on the left key were made predictable for the first time by having each interval consistently associated with a particular key color. If this change resulted in a shift in preference toward the left key, it would show that the previous difference in predictability in favor of the right key had been influencing choice. Conditions $D$ and $F$ involved additional tests of preference for predictability, with two intervals available in each key but the intervals correlated with external stimuli only on the left key. Condition $F$ was a replication of the Bower, McLean, and Meacham (1966) procedure where the first peck to either key in the initial link produced the appropriate terminal link schedule.

\section{Subjects}

Seven experimentally naive male Silver King pigeons, maintained at $80 \%$ of free-feeding weight, served as subjects.

\section{Apparatus}

The experiment was carried out in an automated laboratory controlled by a PDP-8/L computer. Each of five aluminum panels contained three standard Lehigh Valley Electronics pigeon keys mounted in a horizontal row $5.75 \mathrm{~cm}$ center to center, and a grain feeder mounted beneath the keys. The response keys required a minimum force of $15 \mathrm{~g}(0.15 \mathrm{~N})$ to operate. The five experimental panels were set above one another vertically and embedded in the center of a long wall so they were flush with the surface of the wall. Against that wall was a rack containing 90 pigeon cages ( 5 high by 18 long) that were used both as living cages and experimental cages. The backs of the cages against the wall were open, and the rack containing the cages could be moved automatically so that the appropriate set of five cages was positioned in front of the five experimental panels. The pigeons in this experiment were studied one at a time using one of these panels, while pigeons above and below them responded to the other panels in other, independent experiments. At the end of each experimental session, the rack containing all of the cages was moved automatically by the computer, the data for the complete session was typed out, and the session for the next subject was automatically begun.

\section{Procedure}

The subjects were trained by an auto-shaping method (Brown \& Jenkins, 1968) to peck the two side keys using all colors to appear subsequently in the experiment. They were then introduced to the concurrent-chains procedure shown for Condition $A$ in Table 1 by increasing VI values to those shown over a period of five sessions. Throughout the experiment, when a terminal link occurred, the key last pecked turned a different color, the other key-light turned off, and subsequent pecks to the lit key were reinforced according to one of the schedules shown in Table 1. After one reinforcement was received in the terminal link, the concurrent initial links of the two chain schedules were reinstated. Sessions were terminated after 60 reinforcements. Subjects were studied daily under the sequence of conditions shown in Table 1. For each subject, the duration for which the food tray was raised for reinforcement was modified daily to maintain each pigeon at approximately $80 \%$ of free-feeding weight with no food being given outside the experimental session.

\section{RESULTS}

Two major results were obtained. The first, shown in the top panel of Figure 1, was an increase in preference 


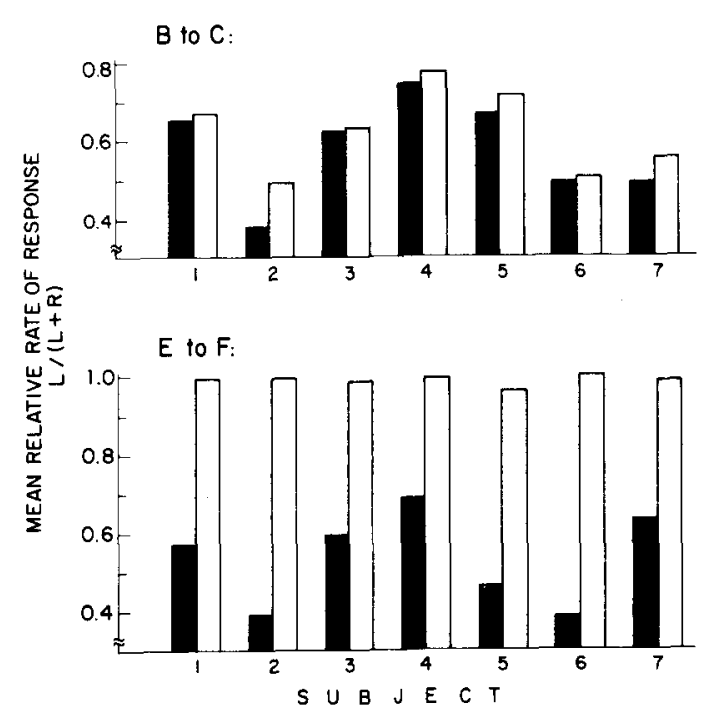

Figure 1. Mean relative rates of responding in the initial links for individual subjects. Top panel: mean preference in the last five sessions of Condition B (filled bars) and the first five sessions of Condition $C$ (open bars). Bottom panel: mean preference in the last five sessions of Condition $E$ (filled bars) and the first five sessions of Condition F (open bars).

for the left key at the onset of Condition $C$, when reinforcement intervals on that key first became predictable in terms of key color. This increase in preference was reliable across subjects and therefore statistically significant (two-tailed $\mathrm{p}=.02$ by a Wilcoxon matchedpairs signed-ranks test), but was small in magnitude and transient. The second result, shown in the bottom panel of Figure 1, was a strong increase in preference for the left (predictive) key at the onset of Condition F, when only one peck was required in the initial links to produce the appropriate terminal-link schedule. This preference was of much greater magnitude than that observed in Condition $\mathrm{C}$ and was again reliable across subjects and statistically significant (two-tailed $p=.02$ by a Wilcoxon matched-pairs signed-ranks test).

Additional data for individual subjects are shown in Table 2. At the end of Condition A, a baseline condition following Davison's (1969) procedure, relative rates of responding were close to .50 for all subjects. In Condition $B$, when red and green replaced yellow on the left key, no clear shifts in preference occurred. Comparing preferences at the end of Condition $A$ to the beginning of Condition B, preference for the left key increased in four subjects, remained the same in one, and decreased in two. Comparing preferences at the end of Condition $\mathrm{A}$ to the end of Condition B, preferences increased in four subjects and decreased in three. This suggests that color preferences were not involved in subsequently observed effects.

In Condition $\mathrm{C}$, when the reinforcement interval on the left key was correlated with key color for the first time, there were for the first time shifts in preference that were consistent across subjects, since relative rate of responding to the left key rose for each subject (Figure 1). However, this change was transient and small in magnitude, the mean increase in relative rate being 0.04 . Because of the small magnitude of the effect, the possibility is raised that the increase observed may simply reflect some general factor such as a gradually rising baseline. Such an account may seem reasonable for one subject (Subject 1, Table 2) but not for others (Subject 2, Table 2). To insure that the consistency of the observed increase across all subjects was not simply due to arbitrary use of 5-day means on either side of the transition from $\mathrm{B}$ to $\mathrm{C}$, additional analyses were made using both 4-day means and 3-day means bracketing the transition. Using 4-day means, again seven of seven subjects showed increases in relative rates of responding, while using 3-day means six of six subjects showed increases (with one tie).

Condition D was an attempt to examine the effects of predictability in a different way, but no reliable shifts in preference occurred at the onset of that condition, and at the end of that condition there was no strong preference for either alternative that was reliable across subjects (Table 2). This may be contrasted with Conditions $E$ and $F$, when initial-link contingencies were changed so that the first peck in the initial link produced the appropriate terminal-link schedule. In this case,

Table 2

Absolute and Relative Response Rates in the Initial Links

\begin{tabular}{|c|c|c|c|c|c|c|c|c|c|c|c|c|c|c|c|c|c|c|c|c|c|}
\hline \multirow[b]{2}{*}{ Condition } & \multicolumn{3}{|c|}{ Subject 1} & \multicolumn{3}{|c|}{ Subject 2} & \multicolumn{3}{|c|}{ Subject 3} & \multicolumn{3}{|c|}{ Subject 4} & \multicolumn{3}{|c|}{ Subject 5} & \multicolumn{3}{|c|}{ Subject 6} & \multicolumn{3}{|c|}{ Subject 7} \\
\hline & $\mathrm{L}$ & & Rel & $\mathrm{L}$ & $\mathrm{R}$ & Rel & L & $\mathrm{R}$ & Rel & $\mathbf{L}$ & $\mathrm{R}$ & Rel & L & $\mathbf{R}$ & Rel & $\mathrm{L}$ & $\mathbf{R}$ & Rel & $\mathbf{L}$ & $\mathbf{R}$ & Rel \\
\hline $\begin{array}{l}\text { B (start) } \\
\text { B (end) } \\
C \text { (start) } \\
C \text { (end) }\end{array}$ & $\begin{array}{l}23.3 \\
19.1 \\
21.7 \\
28.0\end{array}$ & $\begin{array}{r}10.4 \\
10.6 \\
9.2\end{array}$ & $\begin{array}{l}.40 \\
.65 \\
.67 \\
.76\end{array}$ & $\begin{array}{l}26.5 \\
19.8 \\
25.4\end{array}$ & , & $\begin{array}{l}.38 \\
.49 \\
.51\end{array}$ & $\begin{array}{l}15 \\
18 \\
22 \\
24\end{array}$ & $\begin{array}{r}9.8 \\
10.7\end{array}$ & $\begin{array}{l}.58 \\
.61 \\
.62 \\
.63 \\
.62\end{array}$ & $\begin{array}{l}22.6 \\
22.3 \\
23.5 \\
18.2\end{array}$ & $\begin{array}{r}7.9 \\
6.6 \\
10.9\end{array}$ & $\begin{array}{l}.54 \\
.74 \\
.77 \\
.65\end{array}$ & & & $\begin{array}{l}.53 \\
.68 \\
.66 \\
.71 \\
.92\end{array}$ & & $\begin{array}{l}32.9 \\
31.2 \\
21.7 \\
28.4 \\
31.0\end{array}$ & $\begin{array}{l}.54 \\
.59 \\
.49 \\
.50 \\
.48\end{array}$ & $\begin{array}{l}6.5 \\
4.8 \\
7.3 \\
1.8 \\
4.2\end{array}$ & $\begin{array}{l}20.8 \\
21.4 \\
17.8 \\
18.2 \\
18.5\end{array}$ & $\begin{array}{l}.56 \\
.54 \\
.49 \\
.55 \\
.57\end{array}$ \\
\hline D (end) & 24.5 & 14.0 & .63 & 33.6 & 19.9 & .63 & 28.9 & 1.4 & .57 & 22.0 & 15.9 & .60 & 26.2 & 13.5 & .66 & 31.0 & 35.2 & .47 & 20.3 & 25.0 & .45 \\
\hline $\begin{array}{l}E \text { (end) } \\
F \text { (start) }\end{array}$ & $\begin{array}{r}5.1 \\
21.0\end{array}$ & $\begin{array}{r}4.1 \\
.2\end{array}$ & $\begin{array}{l}.57 \\
.99\end{array}$ & $\begin{array}{r}7.0 \\
49.8\end{array}$ & .3 & $\begin{array}{l}.39 \\
.99\end{array}$ & $\begin{array}{r}8.5 \\
26.5\end{array}$ & $\begin{array}{r}6.0 \\
.6\end{array}$ & $\begin{array}{l}.59 \\
.98\end{array}$ & $\begin{array}{l}11.2 \\
39.0\end{array}$ & $\begin{array}{r}5.3 \\
.3\end{array}$ & $\begin{array}{l}.68 \\
.99\end{array}$ & 3.0 & $\begin{array}{r}3.7 \\
.5 \\
\end{array}$ & $\begin{array}{l}.46 \\
.96\end{array}$ & $\begin{array}{r}5.2 \\
23.3\end{array}$ & $\begin{array}{r}8.0 \\
.0\end{array}$ & $\begin{array}{r}.38 \\
1.00\end{array}$ & $\begin{array}{r}7.9 \\
19.9 \\
\end{array}$ & $\begin{array}{r}4.7 \\
.5\end{array}$ & $\begin{array}{l}.63 \\
.98 \\
\end{array}$ \\
\hline
\end{tabular}

Note. Entries are mean absolute rates to the left $(L)$ or right $(R)$ key in responses $/$ min or mean relative rates $(R e l=L /(L+R) /$, for the first five sessions (start) or last five sessions (end) of each condition. 


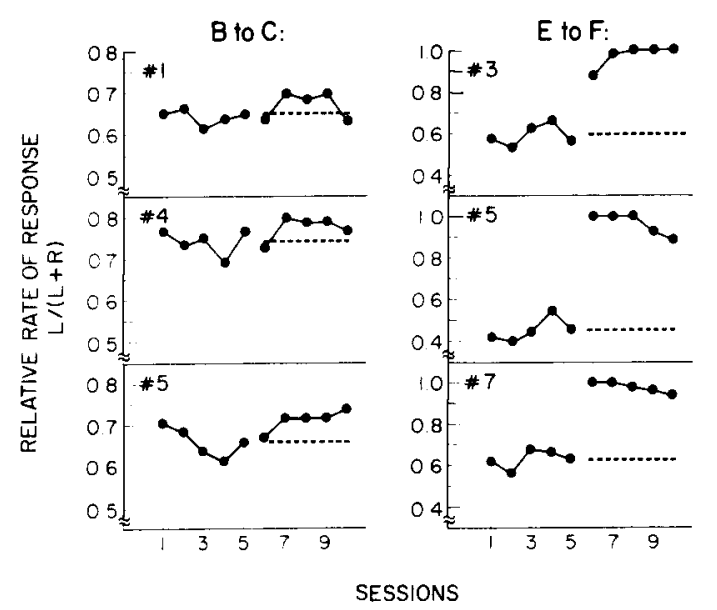

Figure 2. Relative rates of responding in the initial links for individual subjects across single sessions. Left panel: last five sessions of Condition $B$ and first five sessions of Condition $C$. Right panel: last five sessions of Condition $E$ and first five sessions of Condition $F$. In both panels, dashed lines indicate mean relative rate for that subject over the last five sessions in the first condition.

extremely strong and reliable effects on choice occurred when reinforcement intervals on the left key were made predictable: relative rates of responding rose markedly in all subjects from the end of Condition $E$ to the start of Condition F (Figure 1). There was no sign of any diminution of preference throughout the nine sessions of Condition $F$, with all subjects responding to the left key more than $95 \%$ of the time even on the last day of the experiment.

In the two conditions of this experiment where reliable effects occurred, those effects appeared almost immediately. Figure 2 shows relative rates of responding in the initial links across single sessions for individual subjects. The subjects chosen for presentation in Figure 2 were median subjects in terms of their change in mean preference from the end of one condition to the onset of the next as shown in Figure 1, and are representative of the other subjects. At the onset of Condition $\mathrm{C}$, the typical pattern was for a small increase in preference for the left key to appear by the second day and to be maintained for several days. For the subjects shown in Figure 2, the preference observed on the second or third day of Condition $\mathrm{C}$ was greater than that observed in any of the final sessions of Condition $\mathrm{B}$; this was true of six of the seven subjects in the experiment. The shifts in preference from Condition $\mathbf{E}$ to Condittion $F$ were much more dramatic, with all subjects showing a large increase in preference for the left key on the very first session of Condition F. Relative rates of responding in the final session of Condition $E$ averaged 0.54 , while those in the first session of Condition $F$ averaged 0.98 . For every subject, relative rates in each of the first five sessions of Condition $F$ were higher than those in any of the last five sessions of Condition E.

Two additional aspects of the data deserve brief mention. The first concerns the possibility that the increase in preference for the left key observed in Conditions $\mathrm{C}$ and $\mathrm{F}$ occurred simply because relative reinforcement rates in the terminal links increased for some reason in those phases. This was not the case; there were no clear changes in relative reinforcement rates from Conditions $B$ to $C$ or from Conditions $E$ to $F$, as relative reinforcement rates in each case rose for some subjects and dropped for others (Table 3). However, relative number of reinforcements on the left key was greater than on the right key in Condition $\mathrm{F}$ because in that condition there were more entries into the terminal link on the left than on the right key since the initial link was an FR 1.

A final question concerns the effects of the predictive key colors on response rates on terminal links in Conditions $\mathrm{C}$ and $\mathrm{F}$. If initial-link preferences observed in those conditions depended on the reinforcement intervals becoming predicted by key color, we would expect responding during the different intervals in the terminal links to change when the predictive colors became available. Table 4 shows that such an effect did occur. When intervals were not predicted by key color, there typically was a higher mean rate of responding in $45-\mathrm{sec}$ intervals than in 15-sec intervals. This suggests an overall increase in response rate throughout the interval, or a typical "FI scallop." When the intervals became predicted by color in Conditions $\mathrm{C}$ and $\mathrm{E}$, the typical pattern was for response rates in the $15-\mathrm{sec}$ interval to approximately double, ending up higher than response rates in $45-\mathrm{sec}$ intervals.

Table 3

Absolute and Relative Reinforcement Rates in the Terminal Links

\begin{tabular}{|c|c|c|c|c|c|c|c|c|c|c|c|c|c|c|c|c|c|c|c|c|c|}
\hline \multirow[b]{2}{*}{ Condition } & \multicolumn{3}{|c|}{ Subject 1} & \multicolumn{3}{|c|}{ Subject 2} & \multicolumn{3}{|c|}{ Subject 3} & \multicolumn{3}{|c|}{ Subject 4} & \multicolumn{3}{|c|}{ Subject 5} & \multicolumn{3}{|c|}{ Subject 6} & \multicolumn{3}{|c|}{ Subject 7} \\
\hline & $\mathbf{L}$ & $\mathbf{R}$ & Rel & $\mathbf{L}$ & $\mathrm{R}$ & Rel & $\mathbf{L}$ & $\mathrm{R}$ & Rel & L & $\mathbf{R}$ & Rel & $\mathrm{L}$ & $\mathbf{R}$ & Rel & $\mathrm{L}$ & R & Rel & L & $\mathrm{R}$ & Rel \\
\hline $\begin{array}{l}\text { B (end) } \\
C \text { (start) }\end{array}$ & $\begin{array}{l}2.02 \\
1.95\end{array}$ & $\begin{array}{l}3.11 \\
3.13\end{array}$ & $\begin{array}{l}.39 \\
.38\end{array}$ & $\begin{array}{l}1.95 \\
1.98\end{array}$ & $\begin{array}{l}3.10 \\
3.06\end{array}$ & $\begin{array}{l}.39 \\
.39\end{array}$ & $\begin{array}{l}1.95 \\
1.95\end{array}$ & $\begin{array}{l}2.95 \\
3.12\end{array}$ & $\begin{array}{l}.40 \\
.38\end{array}$ & $\begin{array}{l}1.87 \\
1.95\end{array}$ & $\begin{array}{l}3.17 \\
3.16\end{array}$ & $\begin{array}{l}.37 \\
.38\end{array}$ & $\begin{array}{l}2.05 \\
1.99\end{array}$ & $\begin{array}{l}2.90 \\
3.16\end{array}$ & $\begin{array}{l}.42 \\
.39\end{array}$ & $\begin{array}{l}1.94 \\
1.93\end{array}$ & $\begin{array}{l}3.13 \\
3.17\end{array}$ & $\begin{array}{l}.38 \\
.38\end{array}$ & $\begin{array}{l}1.94 \\
2.01\end{array}$ & $\begin{array}{l}3.16 \\
3.16\end{array}$ & $\begin{array}{l}.38 \\
.39\end{array}$ \\
\hline $\begin{array}{l}E \text { (end) } \\
F \text { (start) }\end{array}$ & $\begin{array}{l}1.99 \\
1.98\end{array}$ & $\begin{array}{l}2.02 \\
1.60\end{array}$ & $\begin{array}{l}.50 \\
.56\end{array}$ & $\begin{array}{l}1.97 \\
1.95\end{array}$ & $\begin{array}{l}1.96 \\
2.65\end{array}$ & $\begin{array}{l}.50 \\
.47\end{array}$ & $\begin{array}{l}1.94 \\
1.99\end{array}$ & $\begin{array}{l}1.98 \\
2.71\end{array}$ & $\begin{array}{l}.50 \\
.44\end{array}$ & $\begin{array}{l}1.98 \\
1.93\end{array}$ & $\begin{array}{l}1.95 \\
2.95\end{array}$ & $\begin{array}{l}.50 \\
.41\end{array}$ & $\begin{array}{l}1.97 \\
1.84\end{array}$ & $\begin{array}{l}1.87 \\
1.70\end{array}$ & $\begin{array}{l}.51 \\
.55\end{array}$ & $\begin{array}{l}1.95 \\
1.98\end{array}$ & $\begin{array}{l}1.94 \\
3.15\end{array}$ & $\begin{array}{l}.50 \\
.39\end{array}$ & $\begin{array}{l}1.97 \\
1.90\end{array}$ & $\begin{array}{l}1.94 \\
2.21\end{array}$ & $\begin{array}{l}.50 \\
.47\end{array}$ \\
\hline
\end{tabular}

Note. Entries are mean reinforcement rates on the left $(L)$ or right $(R)$ key in reinforcements/min, or mean relative rates $[R e l=L /(L+R)]$, for the last five or first five sessions of selected conditions. 
Table 4

Response Rate in 15-Sec and 45-Sec Terminal-Link Periods

\begin{tabular}{|c|c|c|c|c|c|c|c|c|c|c|c|c|c|c|c|c|}
\hline \multirow[b]{2}{*}{ Condition } & \multicolumn{2}{|c|}{ Subject 1} & \multicolumn{2}{|c|}{ Subject 2} & \multicolumn{2}{|c|}{ Subject 3} & \multicolumn{2}{|c|}{ Subject 4} & \multicolumn{2}{|c|}{ Subject 5} & \multicolumn{2}{|c|}{ Subject 6} & \multicolumn{2}{|c|}{ Subject 7} & \multicolumn{2}{|c|}{ Mean } \\
\hline & 15 & 45 & 15 & 45 & 15 & 45 & 15 & 45 & 15 & 45 & 15 & 45 & 15 & 45 & 15 & 45 \\
\hline $\begin{array}{l}\text { B (end) } \\
C \text { (start) }\end{array}$ & $\begin{array}{l}40.3 \\
83.4\end{array}$ & $\begin{array}{l}54.0 \\
44.7\end{array}$ & $\begin{array}{l}50.4 \\
88.9\end{array}$ & $\begin{array}{l}73.9 \\
60.8\end{array}$ & $\begin{array}{l}58.8 \\
54.1\end{array}$ & $\begin{array}{l}80.6 \\
78.7\end{array}$ & $\begin{array}{r}33.1 \\
127.6\end{array}$ & $\begin{array}{l}53.1 \\
53.5\end{array}$ & $\begin{array}{l}41.9 \\
78.2\end{array}$ & $\begin{array}{l}56.4 \\
63.6\end{array}$ & $\begin{array}{r}59.5 \\
141.0\end{array}$ & $\begin{array}{l}73.7 \\
89.5\end{array}$ & $\begin{array}{l}46.4 \\
67.5\end{array}$ & $\begin{array}{l}79.0 \\
83.0\end{array}$ & $\begin{array}{l}47.2 \\
91.5\end{array}$ & $\begin{array}{l}67.2 \\
67.7\end{array}$ \\
\hline $\begin{array}{l}E \text { (end) } \\
F \text { (start) }\end{array}$ & $\begin{array}{l}45.2 \\
80.6\end{array}$ & $\begin{array}{l}65.0 \\
44.6\end{array}$ & $\begin{array}{r}70.3 \\
134.9\end{array}$ & $\begin{array}{l}97.7 \\
68.4\end{array}$ & $\begin{array}{l}54.7 \\
92.7\end{array}$ & $\begin{array}{l}82.0 \\
77.2\end{array}$ & $\begin{array}{r}49.6 \\
118.3\end{array}$ & $\begin{array}{l}78.6 \\
45.0\end{array}$ & $\begin{array}{l}25.7 \\
94.0\end{array}$ & $\begin{array}{l}51.0 \\
39.5\end{array}$ & $\begin{array}{r}58.9 \\
170.6\end{array}$ & $\begin{array}{l}73.0 \\
74.6\end{array}$ & $\begin{array}{l}46.4 \\
27.5\end{array}$ & $\begin{array}{l}66.1 \\
53.5\end{array}$ & $\begin{array}{r}50.1 \\
102.7\end{array}$ & $\begin{array}{l}73.3 \\
57.5\end{array}$ \\
\hline
\end{tabular}

Note. Entries are mean rates in responses/min for the last five or first five sessions of selected conditions.

\section{DISCUSSION}

There was evidence for an effect of predictability on preference in this experiment, but the magnitude of the effect depended on experimental conditions. In each of Conditions $\mathrm{C}, \mathrm{D}$, and $\mathrm{F}$, reinforcement intervals were predicted by key color on the left key but not on the right key. In Conditions $\mathrm{C}$ and $\mathrm{D}$, when VI $60-\mathrm{sec}$ initial-link schedules were used, no consistent effect was observed in one case (D) while in the other case (C) a reliable effect on choice was observed, although small in magnitude. On the other hand, a large and reliable effect was obtained in Condition F with FR 1 initial-link schedules. The finding in Condition $\mathrm{F}$ is consistent with the earlier data of Bower, McLean, and Meacham (1966) whose study also incorporated control conditions showing that the observed preference was not simply based on color preferences. The present findings are also supported by the findings of Hursh and Fantino (1974), who examined preference for mixed vs. multiple schedules using a concurrent-chains procedure similar to that employed here. Each of two pigeons showed reliable and repeatable preference for the multiple schedule, in which two key colors were correlated with two reinforcement intervals, over a mixed schedule in which the two key colors and the two reinforcement intervals were uncorrelated. Also consistent with the present results, the preferences Hursh observed were weak when VI 60-sec initial-link schedules were used but stronger when VI 15-sec initial-link schedules were used: relative rates of responding in initial links for the two subjects averaged .55 and .67 in the former case, .72 and .90 in the latter case.

Most previous concurrent-chains studies have used VI 60-sec initial-link schedules, but few studies have used FR 1 initial-link schedules (Bower, McLean, and Meacham, 1966; Davison, 1968). The present study seems to be the first where these two different types of initial-link schedules were directly compared. The finding of a stronger effect on choice with FR 1 schedules is consistent with an earlier study by Fantino (1969), who examined preference between VI 30-sec and VI 90-sec terminal-link schedules using initial-link schedules that were either VI 40-sec, VI 120-sec, or VI 600 -sec. Fantino found stronger preferences using shorter VI schedules in the initial links. Since the FR 1 initial-link schedules used here can be viewed as VI schedules of 0 -sec duration, the present finding of extremely strong preferences with FR 1 initial-link schedules is consistent with Fantino's data.

There are several reasons why relative rates of responding might be more extreme with FR 1 initial-link schedules than with VI 60-sec initial-link schedules. One possibility is simply that initial-link responses have more direct consequences with FR 1 schedules, and are therefore more sensitive to terminal-link differences. Another possibility is that with FR 1 schedules, as soon as some preference occurs the relative number of reinforcements received becomes greater with the preferred than the nonpreferred alternative, since a preference for an FR 1 initial link will result in a greater number of entries into the terminal link of the preferred key. This feedback effect would increase the strength of any initial preference that occurred. Finally, with VI 60 -sec initial-link schedules, but not with FR 1 initial-link schedules, there are reasons for subjects to make at least some responses on the less preferred alternative. This is because, with VI 60-sec initial-link schedules, the occurrence of some initial-link responses to the less preferred alternative significantly increases overall rate of reinforcement throughout the session as compared to what could be obtained if only one key were pecked in initial links. ${ }^{1}$ No parallel reason for pecking the nonpreferred alternative exists with FR 1 initial links. There are therefore several reasons why more extreme preference might be expected using FR 1 initial-link schedules than using VI 60-sec initial-link schedules. These reasons differ from the explanation offered by Fantino (1969) for the results of his experiment described above, since they imply that any preference will be stronger using shorter initial-link schedules, not just differences in time to reinforcement in terminal links. As one example, the present arguments imply that preference between terminal links associated with the same schedule of reinforcement but different magnitudes of reinforcement would be greater using shorter initial-link schedules, while Fantino's (1969) original account does not imply such an effect.

In summary, the results of the present study suggest that preference between fixed and variable schedules may be influenced both by temporal scaling and by predictability of the reinforcement intervals, and that 
the effect of predictability varies with the length of the initial link. Such relationships have not been isolated in previous studies examining preference between FI and VI schedules of reinforcement.

\section{REFERENCES}

Bower, G., McLean, J., \& Meacham, J. Value of knowing when reinforcement is due. Joumal of Comparative and Physiological Psychology, 1966, 62, 181-192.

Brown, P. L., \& Jenkins, H. M. Auto-shaping of the pigeon's key-peck. Journal of the Experimental Analysis of Behavior. $1968,11,1-8$.

Davison. $M$, C. Reinforcement rate and immediacy of reinforcement as factors in choice. Psychonomic Science, 1968, 10 , 181-182.

Davison, M. C. Preference for mixed-interval versus fixed-interval schedules. Journal of the Experimental Analysis of Behavior, 1969. 12. 247-252.

Davison, M. C. Preference for mixed-interval versus fixed-interval schedules: number of component intervals. Journal of the Experimental Andysis of Behavior, 1972, 17, 169-176.

Duncan, B, \& Fantino, E. Choice for periodic schedules of reinforcement. Joumal of the Experimental Analysis of Behavior. 1970, 14, 73-86.

Fantino, E. Preference for mixed- versus fixed-ratio schedules. Journal of the Experimental Analysis of Behavior,1967, $10,35-43$.
Fantino, E. Choice and rate of reinforcement. Journal of the Experimental Analysis of Behavior, $1969,12,723-730$

Herrnstein, R. J. Secondary reinforcement and rate of primary reinforcement. Journal of the Experimental Analysis of Behavior, 1964, 7, 27-36. (a)

Herrnstein, R. J. A periodicity as a factor in choice. Journal of the Experimental Analysis of Behavior, 1964, 7, 179-182, (b)

Hursh, S. R., \& Fantino, E. An appraisal of preference for multiple versus mixed schedules. Journal of the Experimental Analysis of Behavior, 1974, 22, 31-38.

Killeen, $P$. On the measurement of reinforcement frequency in the study of preference. Journal of the Experimental Analy sis of Behavior, 1968, 11, 263-269.

Navarick, D. J., \& Fantino, E. Transitivity as a property of choice. Journal of the Experimental Analysis of Behavior, $1972,18,389-401$.

\section{NOTES}

1. In Condition $D$ of the present experiment, for instance, if only one key were pecked in the initial link, the overall rate of reinforcement would average one reinforcement every $90 \mathrm{sec}$ (average 60-sec initial link plus average 30-sec terminal link) while if both keys were pecked in the initial link, the overal rate of reinforcement would average one reinforcement every 60 sec (average $30-\mathrm{sec}$ initial link until one of the terminal links occurred plus average 30-sec terminal link).

(Received for publication March 18, 1975 . Revision accepted August 7,1975 .) 